\title{
PENERAPAN METODE E-LEARNING DALAM RANGKA PENINGKATAN KUALITAS PEMBELAJARAN PADA SUASANA COVID-19
}

\author{
Megaria Purba \\ Manajemen Informatika, AMIK WIDYALOKA Medan \\ ${ }^{1}$ Jl.Gereja Zaitun No 29 DSN IV Tg.Gusta Kecamatan Sunggal Kabupaten Deli Serdang Propinsi \\ Sumatera Utara Indonesia* megariapurba18@gmail.com \\ Fenisa Lourence Tobing \\ Manajemen Informatika, AMIK WIDYALOKA Medan \\ ${ }^{1}$ Jl.Gaperta Ujung Komp.The Mansion Gaperta No.C7 Kecamatan Medan Helvetia Kota Medan \\ Propinsi Sumatera Utara Indonesia*fenishatobing@gmail.com \\ Sanna Yolanda Silaen \\ Manajemen Informatika, AMIK WIDYALOKA Medan \\ ${ }^{1}$ Jl.Pendidikan Sehati No.54 Kecamatan Medan Perjuangan Kota Medan Propinsi Sumatera Utara \\ Indonesia* yolandasilaen28@gmail.com
}

\begin{abstract}
Abstrak
Kualitas pembelajaran khususnya bidang studi matematika dipengaruhi beberapa faktor salah satu dari faktor tersebut adalah metode mengajar dan system belajar yang tanpa dibatasi waktu dan ruang yang disebut e-learning.

Pembelajaran yang terjadi pada SMP Free Methodist 1 Medan belum mencapai kompetensi memuaskan karena masih menggunakan metode guru menjelaskan didepan (verbal) kelas dan siswa mendengarkan dan kemudian memberikan latihan penyelesaian soal soal. Hal ini pembelajaran didominasi oleh guru (berpusat pada guru) yang monoton sehingga membosankan siswa akhirnya pelajaran matematika dianggap sulit dan kurang diminati.

Untuk mengatasi permasalahan tersebut perlu pembuatan bahan ajar matematika berbasis emateri dan penginputan ke aplikasi e-learning yang dapat meningkatkan kualitas bahan ajar guru serta menambah minat belajar siswa.

Pada penelitian ini akan dilakukan mulai observasi dan wawancara untuk pengumpulan data, kemudian data diolah dan dianalisis untuk mendapatkan tingkat kualitas pembelajaran yang sedang berlangsung. Selanjutnya akan dilakukan pembuatan e-materi dan penginputan ke aplikasi e-learning sampai ketahap bahan ajar. E-learning yang sudah divalidasi diimplementasikan ke SMP Free Methodist 1 Medan hasilnya diolah dan dianalisis untuk mrndapatkan tingkat pengaruh kualitas pembelajaran.
\end{abstract}

\section{Kata kunci : Penerapan, Metode, e-learning, Matematika}

\section{Pendahuluan}

\subsection{Latar Belakang}

Sampai saat ini pemerintah berupaya untuk meningkatkan kualitas pendidikan di Indonesia sesuai dengan undang undang pendidikan.Masalah kualitas ini berhubungan dengan penyediaan materi dan bahan belajar yang dapat diakses secara luas tanpa dibatasi oleh kendala jarak dan waktu. Apabila kendala ini dapat diatasi maka misi untuk menerapkan pendidikan sepanjang hayat pada segenap lapisan masyarakat dapat diwujudkan. Dalam mewujudkan hal ini dibutuhkan perubahan pada paradigma proses belajar mengajar yang telah diterapkan selama ini. Kepuasan pengguna jasa pendidikan dalam hal ini adalah Siswa/Siswi merupakan faktor yang sangat penting dalam peningkatan mutu layanan pendidikan, sehingga harus dilayani dengan baik. 
Berdasarkan pengamatan dilapangan pembelajaran yang dilakukan pada SMP Free Methodist 1 Medan adalah dengan menggunakan metode guru menerangkan di depan kelas dan siswa mendengarkan kemudian guru memberikan latihan penyelesaian soal-soal dan pekerjaan rumahdan selama suasana covid 19 hanya dengan menggunakan wa grup untuk pemberitahuan pengumpulan pekerjaan rumah dan pengambilan soal [antar dan jemput pr ke sekolah]. Dengan metode yang dilakukan selama ini siswa siswi memberikan alasan matematika adalah sulit dan membosankan akibatnya kompetensi siswa kurang memuaskan dengan angka nilai raport dominan 6 sampai 7 . Untuk meningkatkan minat dan prestasi siswa terhadap mata pelajaran matematika maka perlu peningkatan kualitas pembelajaran dengan menggunakan metode $e$-learning yang menimbulkan daya tarik dengan memanfaatkan perkembangan teknologi dan informasi .

E-learning adalah suatu model pembelajaran yang dibuat dalam format digital melalui perangkat elektronik ( menggunakan jasa audio,video atau perangkat komputer atau kombinasi dari ketiganya). Sistem e-learning yang dimiliki suatu intitusi pendidikan merupakan investasi yang sangat penting untuk meningkatkan kualitas guru dalam mengajar. Sistem ini dapat membantu menciptakan budaya belajar dan mengajar yang fleksibel sesuai dengan perkembangan tuntutan kebutuhan pembelajaran.

SMP Free Methodist 1 Medan, sudah memiliki komputer dan Sistem Informasi dengan jaringan internet sehingga dimungkinkan untuk dikembangkan paket belajar Personal-Interaktif yang materi ajarnya dikemas dalam suatu software. Peserta dapat belajar dengan Pemanfaatan e-learning tidak terlepas dari jasa internet dengan proses belajar dan mengajar tidak hanya didominasi oleh peran guru dan buku tetapi juga teknologi. Materi pelajaran didesain seolah peserta didik belajar di hadapan pengajar melalui layar komputer yang dihubungkan melalui jaringan internet. Untuk dapat menghasilkan e-learning yang menarik dan diminati, maka e-learning perlu dibuat seolah-olah peserta didik belajar dalam situasi belajar dalam sistem digital melalui internet. Melakukan variasi cara mengajar untuk mencapai dasar kompetensi yang ingin dicapai melakukan penilaian dengan memanfaatkan dengan bantuan, teknologi yang ada, menggunakan komputer, online assessment system) menyediakan material pembelajaran seperti buku, multimedia, studio yang memadai. Materi pembelajaran yang disimpan di komputer dapat diakses dengan mudah baik oleh guru maupun siswa.

Guru bidang studi matematika Sekolah Menengah Free Methodistt 1 Medan adalah guru yang berkemampuan untuk menerapkan dalam pembelajaran e-learning hal ini dapat dibuktikan dari latar belakang pendidikan yang memang alumni sarjana pendidikan matematika sudah memiliki sertifikat guru profesional.

\subsection{Permasalahan}

a. Bagaimana meningkatkan kulitas pembelajaran matematika yang monoton dan membosankan menjadi menarik dan interaktif pada SMP Free Methodist 1 Medan Kecamatan Medan Helvetia Propinsi Sumatera Utara.

b. Bagaimana menerapkan metode e-learning yang tepat pada bidang study matematika pada SMP Free Methodist 1 Medan.

c. Berapa besar tingkat kualitas pemebelajaran bidang studi matematika setelah metode pemebelajaran e-learning di implementasikan.

1.3. Tujuan Penelitian

a. Memodifikasi bahan ajar matematika menjadi e-materi kedalam aplikasi e-learning yang vailid.

b. Menerapkan metode e-learning selama satu semester pada kelas 7 SMP Free Methodist 1 Medan.

c. Meganalisis berapa besar pengaruh tingkat kualitas pembelajaran bidang studi matematika kelas 7 SMP Free Methodist 1 Medan setelah menggunakan e-learning.

1.4. Manfaat Penelitian

a. Membantu SMP Free Methodist 1 Medan dalam rangka peningkatan kualitas pembelajaran khususnya bidang studi matematika. 
b. Menjadi bahan literatur pembuatan e-learning.

\section{Tinjauan Literatur}

Penelitian Megaria dan Lenaria 2013 berjudul Peningkatan Aksesabilitas Matakuliah Matematika Diskrit Melalui Pemberdayaan E-Learning hasil penelitian menunjukkan bahwa penerapan pembelajaran e-learning dapat meningkatkan kualitas pembelajaran. Megaria Purba, 2014, Seminar Nasional Pembangunan Berkelanjtan Bangsa Berbasis IPTEK Prosiding Penerapan Metode E-learning Pada Bidang Studi Matematika. Electronic Learning biasa disingkat dengan E-learning, yang berarti pembelajaran dengan menggunakan jasa bantuan perangkat elektronika. Dalam pelaksanaannya e-learning menggunakan jasa audio, video atau perangkat computer atau kombinasi dari ketiganya. Dengan kata lain e-learning adalah pembelajaran yang pelaksanaannya didukung oleh jasa teknologi seperti telepon, audio, video tape, transmisi satelit atau komputer. Banyak hal yang mendorong mengapa e-learning menjadi pilihan untuk peningkatan mutu pendidikan antara lain pesatnya fasilitas teknologi informasi dan perkembangan pengguna internet di dunia saat ini berkembang dengan cepat. Penggunaan internet menjadi suatu kebutuhan dalam mendukung pekerjaan atau tugas sehari hari. Apalagi dengan tersedianya fasilitas jaringan (internet infrastructure) dan koneksi internet (internet connections) serta tersedianya piranti lunak pembelajaran (management course tools). Juga orang yang terampil mengoperasikan atau menggunakan internet semakin meningkat jumlahnya (Soekartawi, 2002)

Matematika Sebagai ilmu dasar yang terpakai disegala bidang ilmu pengetahuan sehingga pemerintah melalui Depdiknas menerbitkan kurikulum matematika untuk siswa SMP. Materi matematika menurut Sukrisno/Nelson yang diterapkan pada SMP kelas VII semester II memiliki beberapa standar kompetensi bilangan, aljabar dan geometri yang disusun berdasarkan masing-masing kompetensi seperti pada tabel 1 berikut.

Tabel 1 Kompetensi Pembelajaran

\begin{tabular}{ll}
\hline Standard Kompetensi & Kompetensi Dasar \\
\hline Menggunakan konsep & Memahami pengertian dan notasi himpunan serta penyajianya \\
himpunan dan diagram & Memahami konsep himpunan bagian \\
ven dalam pepecahan & Melakukan operasi irisan,gabungan,kurang dan komplemen pada \\
masalah & himpunan \\
& Menyajikan himpunan dengan diagram ven \\
& Menggunakan konsep himpunan dalam pemecahan masalah \\
\hline & Menetukan hubungan antara dua garis serta besar dan jenis \\
Geometri & Sudutnya \\
& Memahami sifat sifat sudut yang terbentuk \\
& Melukis sudut \\
& Membagi sudut \\
\hline
\end{tabular}

\section{Metode Penelitian}

Melakukan Observasi Lapangan dengan pengamatan langsung selama satu semester dan wawancara kepada guru bidang study matematika dan siswa dan pihak manajemen Sekolah Free Methodist 1 Medan yang beralamat di Jalan Beringin Raya No 152 Kecamatan Medan Helvetia Kota Medan Propinsi Sumatera Utara.

Merancang dan membangun aplikasi $e$ - learning dimulai dengan menetapkan silabus dan bahan ajar yang digunakan akan dikemas menjadi e.materi kemudian diinput kehalaman web aplikasi $e$ learning yang vailid.

Pembelajaran e-learning dapat dilakukan apabila memiliki alat teknologi perangkat keras dan perangkat lunak.seperti:

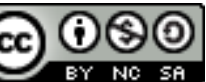


a. Jaringan internet

Jaringan internet adalah untuk pembelajaran yang sudah ada akan di upload ke jaringan internet agar pembelajaran terjadi tidak terbatas dengan waktu dan ruang. Jaringan internet di yayasan katolik mariana sudah ada dan aktif sehingga untuk mengadakan pembelajaran $e$ learning bisa dilaksanakan yang gambaranya adalah seperti tampilan gambar 1:

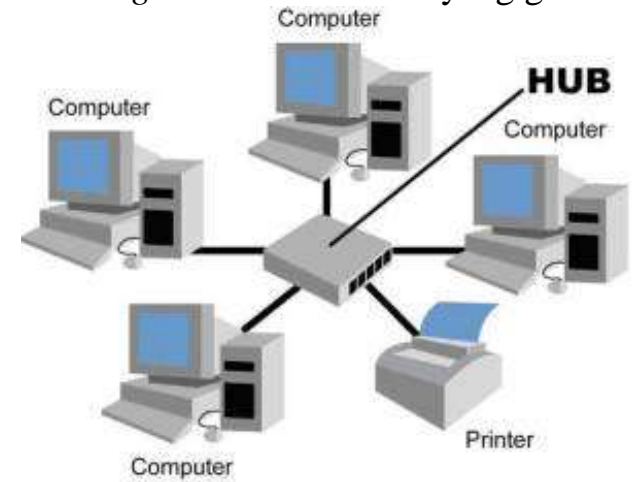

Gambar 1 Jaringan internet

b. Perangkat keras

Laptop pada umumnya sudah memiliki teknologi yang memiliki fersi multi media alat ini digunakan untuk mengadakan media e-pembelajaran yang melibatkan multi media. Pada penelitian ini menggunakan laptop perangkat lunak sistem operasi windows 7, data base Xampp 5.6 dan dan perangkat keras dengan prosesor intel(R) core(TM)i3, Ram 2 GB system operasi 64 bit.

c. Handycam

Digunakan untuk perekam dalam bentuk video yang di hubungkan dengan komputer untuk dapat diedit.

d. Penyewaan Hosting (modem)

Penggunaan penyewaan hosting yang berisikan pulsa untuk menghubungkan jaringan antar jaringan yang lain secara intranet dan internet

e. Sofware ( perangkat lunak)

Sebagai tempat pengaksessan bahan ajar yang akan diupload sesuai dengan bentuk aplikasi yang digunakan seperti pada gambar 2

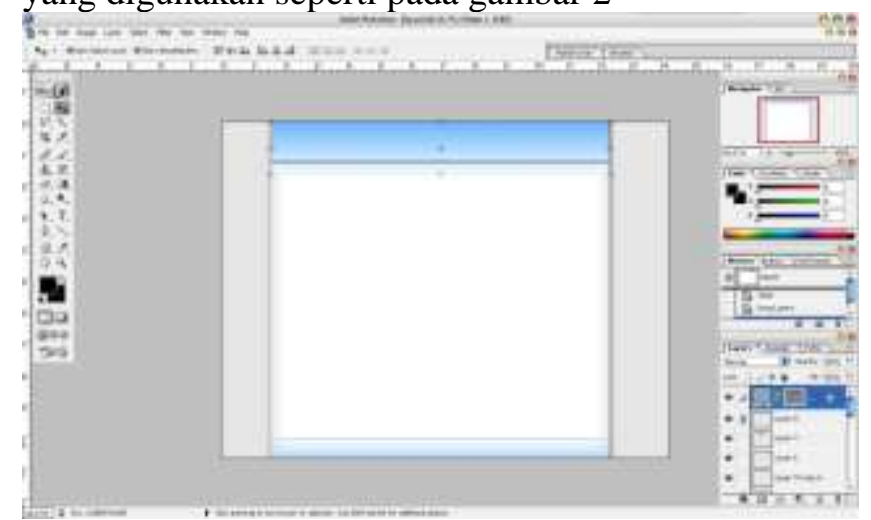

\section{Gambar 2 Perangkat lunak pembangunan aplikasi}

f. Materi

Materi yang sesuai dengan silabus dan kompetensi akan di robah dalam bentuk e-materi adalah mata pelajaran bidang studi matematika kelas 7 sesuai dengan silabus yang digunakan pada sekolah SMP Free Methodist 1 Medan Kecamatan Helvetia Medan Propinsi Sumatera Utara. 
Melatih penggunaan aplikasi yang sudah vailid terhadap guru bidang studi matematika pada sekolah menegah pertama RK Bunda Mulia Saribu Dolok serta siswa yang menggunakanya

Implementasi e-learning selama satu semester dilakukan kepada siswa kelas VII semester 1

Mengolah serta menganalisis data untuk mengetahui tingkat pengaruh menggunakan metode regresi linier sederhana, dengan melihat hasil raport atau wawancara kepada pengguna e-learning selama satu semester.

\section{Hasil dan Pembahasan}

\subsection{Hasil Observasi} adalah:

Berdasarkan hasil observasi kepihak sekolah SMP Free Methodist 1 Medan Helvtia yang didapat

1. Jumlah Siswa Terdiri dari 640 orang dan 16 kelas dimana setiap kelas rata rata 40 orang.

2. Sampel penelitian diambil kelas VII dengan nilai akhir bidang study matematika rata rata 77

3. Jumlah guru bidang study matematika SMP Free Methodist 1 Medan Helvetia 2 orang.

4. Pembelajaran bidang study matematika dilaksanakan guru dan siswa adalah menggunakan kurikulum 2013 dimana selama ini menggunakan metode pelaksanaan dominan guru menerangkan didepan kelas dan siswa duduk mendengarkan kemudian diberikan soal latihan untuk dikerjakan.

5. Pendapat siswa yang diwawancara langsung mengatakan bahwa $80 \%$ berpendapat pelajaran matematika adalah yang sulit dan menakutkan.

6. Pendapat guru yang diwawancarai langsung menyampaikan bahan dengan menerangkan didepan kelas mengalami kesulitan karena penjelasan dengan berulang kali dengan topik yang sama agar siswa dapat memahami.

\subsection{Aplikasi E-learning}

Sesuai denga silabus dan bahan ajar manual yang ada pada SMP Free Methodist 1 Medan maka aplikasi e-learning dimodifikasi sesuai dengan kebutuhan dan hasil yang dimodifikasi dengan tampilan halaman utamanya adalah eperti pada gambar 3. Pada tampilan utama akan link dengan pilihan tampilan bahan ajar yang dikemas dengan bentuk : PDF,PPTX,AVI, dan HTML

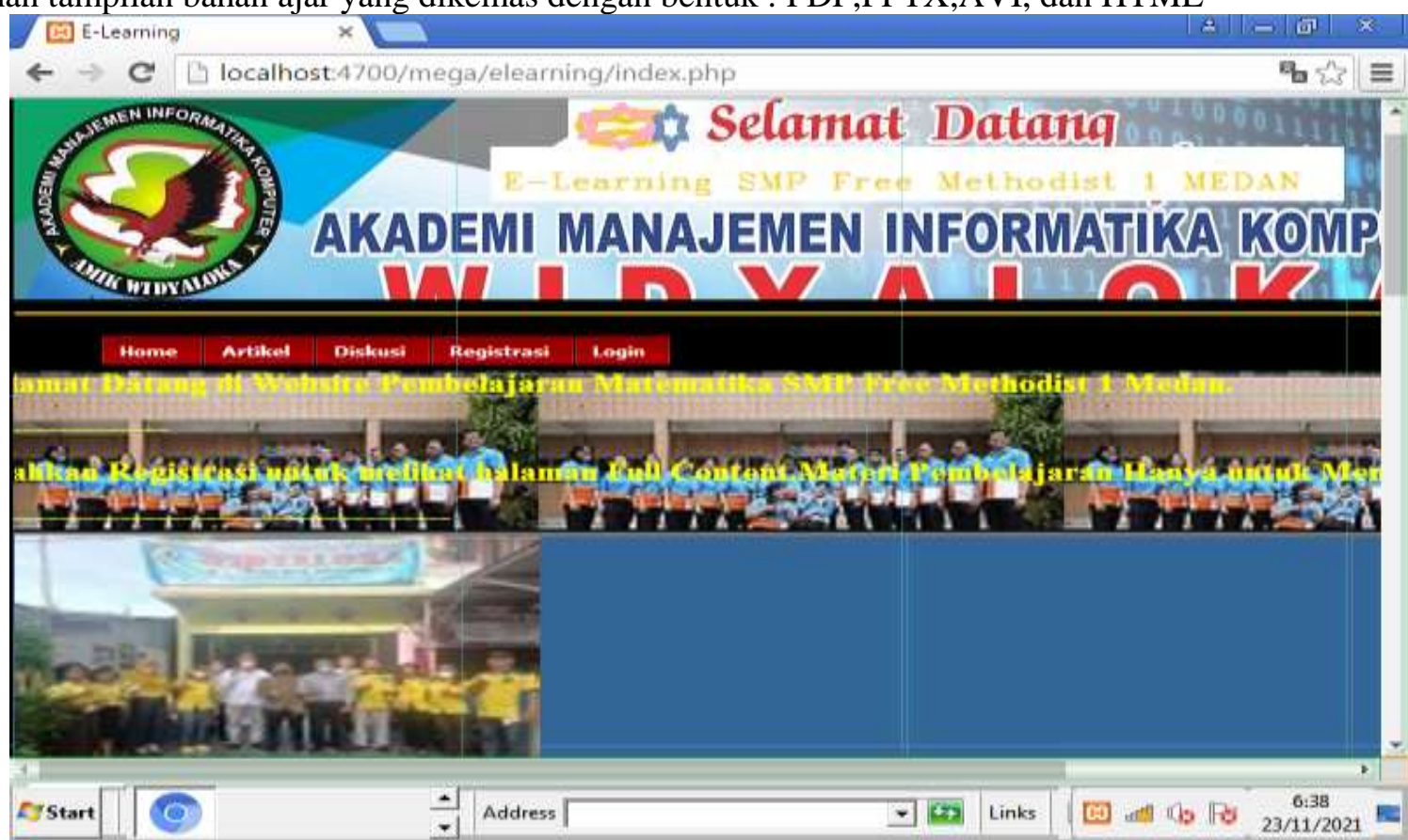

Gambar 3 Tampilan Aplikasi Halaman Utama E-learning 
https://jurnal.amikwidyaloka.ac.id/index.php/awl

jurnal@amikwidyaloka.ac.id / editor.jurnalwidya@gmail.com

\subsection{Implementasi e-learning}

Implementasi e- learning dilakukan selama satu semester yang diterapkan pada kelas VII-c dengan bidang study matematika dengan silabus yang diplih adalah sepeti pada tabel 2

Tabel 2 Kompetensi Pembelajaran

\begin{tabular}{lll}
\hline Pokok Bahasan & Sub Pokok Bahasan & Format \\
\hline \multirow{3}{*}{ Himpunan } & Pengertian & pdf \\
& Penyajian Himpunan & avi \\
& Jenis Himpunan & hhtml \\
& Operasi Himpunan a & avi \\
& Sudut & pdf \\
& Garis & pdf \\
& Perbandingan segmen garis & ppx \\
Sudut Dan Garis & Aplikasi sudut & ppx \\
& & \\
& Segi empat & avi \\
& Segi tiga & avi \\
Bangun Datar & Menghitung besaran segitiga & pdf
\end{tabular}

\subsection{Pengaruh E-Learning}

Rata rata nilai matematika setelah menerapkan e-learning lebih meningkat menjadi 78 dari hasil sebelum menggunakan e-learning rata rata nilai matematika adalah 70 . Berdasarkan persentase maka peningkatan kualitas pembelajaran $11,4 \%$ dan hasil ini diakibatkan bahwa penggunaan e-learning akan meningkatkan minat siswa belajar karena lebih menarik dan mudah dipahami serta tidak dibatasi waktu dan ruang untuk belajar.

Berdasarkan wawancara setelah implementasi maka pendapat siswa yang menggunakan elearning lebih proaktif di luar jam sekolah dalam hal mengulang pembelajaran dan bahan ajar yang dikemas lebih menarik untuk dipelajari dibandingkan yang selama ini berupa hasil catatan yang ditulis dari papan tulis sewaktu di kelas .

\section{Kesimpulan}

Dari hasil penelelitian yang sudah dilakukan maka pembelajaran yang dilakukan SMP Free Methodist 1 Medan yang selama ini dengan menggunakan manual,dan selama suasana covid 19 hanya menggunakan bantuan wa grup, bila menerapkan pembelajaran e-learning maka kualitas pembelajaran akan lebih meninkangkat, dan anak didik lebih tertarik untuk belajar khususnya mata pelajaran matematika.

\section{Referensi}

[1] Megaria Purba, 2014, Penerapan Metode E-learning Pada Bidang Studi Matematika, Medan "Seminar Nasional Pembangunan Berkelanjtan Bangsa Berbasis IPTEK Prosiding,Hal 190-196

[2] Megaria Purba, 2013."Peningkatan Aksesabilitas Matakuliah Matematika Diskrit Melalui Pemberdayaan E-Learning,Medan"Pelita Informatika budidarma,Vol IV No 1 Hal 60-70.

[3] Riyanto. 2015. XAMPP. Yogyakarta: Gava Media.

[4] Soekartawi, 2002. Prospek pembelajaran melalui internet, Makalah pada Seminar Nasional Jakarta:Teknologi Kependidikan

[5] Ifan Junaedi, Dimas Abdillah, Verdi Yasin (2020) “ANALISIS PERANCANGAN DAN PEMBANGUNAN 
APLIKASI BUSINESS INTELLIGENCE PENERIMAAN NEGARA BUKAN PAJAK KEMENTERIAN KEUANGAN RI", Journal of Information System, Applied, Management, Accounting and Research, e-ISSN: 2598-8719. p-ISSN: 2598-8700.Vol.4 No.3 (14 Agustus 2020) p88-101 http://journal.stmikjayakarta.ac.id/index.php/jisamar/article/view/249

[6] Verdi Yasin (2012) Rekayasa Perangkat Lunak Berorientasi Objek, Jakarta: "Mitra Wacana Media".

[7] Anis Rohmadi, Verdi Yasin (2020) "DESAIN DAN PENERAPAN WEBSITE TATA KELOLA PERCETAKAN PADA CV APICDESIGN KREASINDO JAKARTA DENGAN METODE PROTOTYPING", Journal of Information System, Informatics and Computing._E-ISSN: 2597-3673 (Online), P-ISSN: 2579-5201 (Print) Vol. 4 No.1, June 22, 2020. Pp.70-85 http://journal.stmikjayakarta.ac.id/index.php/jisicom/article/view/210

[8] Septian Cahyadi, Verdi Yasin, Mohammad Narji, Anton Zulkarnain Sianipar (2020) "PERANCANGAN SISTEM INFORMASI PENGIRIMAN DAN PENERIMAAN SOAL UJIAN BERBASIS WEB ( STUDI KASUS: FAKULTAS KOMPUTER UNIVERSITAS BUNG KARNO)", Journal of Information System, Informatics and Computing._E-ISSN: 2597-3673 (Online), P-ISSN: 2579-5201 (Print) Vol. 4 No.1, June 22, 2020. Pp.1-16 http://journal.stmikjayakarta.ac.id/index.php/jisicom/article/view/199

[9] Ifan Junaedi, Ndaru Nuswantari, Verdi Yasin (2019) "PERANCANGAN DAN IMPLEMENTASI ALGORITMA C4.5 UNTUK DATA MINING ANALISIS TINGKAT RISIKO KEMATIAN NEONATUM PADA BAYI", Journal of Information System, Informatics and Computing._E-ISSN: 2597-3673 (Online), P-ISSN: 2579-5201 (Print) Vol. 3 No.1, February 13, 2019. Pp.29-44. http://journal.stmikjayakarta.ac.id/index.php/jisicom/article/view/203

[10] Ito Riris Immasari, Verdi Yasin (2019) "PENGGUNAAN METODE ANALYTIC HIERARCHY PROCESS UNTUK MENGANALISIS FAKTOR-FAKTOR YANG MEMPENGARUHI PEMILIHAN CALON LEGISLATIF DI DPRD II KOTA TANGERANG”, Journal of Information System, Informatics and Computing. E-ISSN: 2597-3673 (Online), P-ISSN: 2579-5201 (Print) Vol. 3 No. 2, December 10, 2019. Pp.53-58. http://journal.stmikjayakarta.ac.id/index.php/jisicom/article/view/139

[11] Verdi Yasin, Azhar Ahmad Riza, Rumadi Hartawan (2017) "PENGEMBANGAN APLIKASI PEMULIHAN LAYANAN BENCANA SISTEM INFORMASI PENERIMAN NEGARA BUKAN PAJAK ONLINE DI LINGKUNGAN KEMENTERIAN KEUANGAN REPUBLIK INDONESIA", Journal of Information System, Informatics and Computing. E-ISSN: 2597-3673 (Online), P-ISSN: 2579-5201 (Print) Vol. 1 No. 1, September 20, $2017 . \quad$ Pp.33-56. http://journal.stmikjayakarta.ac.id/index.php/jisicom/article/view/4 